\title{
ANÁLISE DO PROTECIONISMO BRASILEIRO PÓS-CRISE DE 2008: BARREIRAS COMERCIAIS E PLANOS DE INCENTIVOS À INDÚSTRIA
}

\author{
Felippe Rocha Presado Menezes de Barros \\ Mestre em Economia Aplicada pela Universidade Federal de Alagoas. \\ Professor Auxiliar Substituto da Universidade Federal de Alagoas. \\ Maceió, AL, Brasil. \\ Valber Gregory Barbosa Costa Bezerra Santos \\ Mestre em Economia Aplicada pela Universidade Federal de Alagoas. \\ Economista do Tribunal de Justiça do Estado de Alagoas. \\ Maceió, AL, Brasil.
}

\begin{abstract}
RESUMO - A partir do início da crise financeira de 2008, barreiras comerciais foram estabelecidas ao redor do globo como forma de defesa das indústrias e da saúde econômica de respectivos países, cabendo destaque especial para o Brasil, um dos países que mais praticou barreiras comerciais na América Latina. No mesmo período, o Brasil retoma o uso de política industrial de forma explícita, denominada de Plano de Desenvolvimento Produtivo (PDP), sucedida pelo Plano Brasil Maior (PBM), demonstrando abertamente o intuito protecionista do Estado brasileiro. Desta forma, o objetivo deste trabalho é investigar o nível de protecionismo do Estado brasileiro e discutir até que ponto é garantido o fortalecimento da indústria nacional em termos de competitividade e inovação.
\end{abstract}

Palavras-chave: Barreiras comerciais; política industrial; Brasil.

\section{ANALYSIS OF THE POST-CRISIS BRAZILIAN PROTECTIONISM OF 2008: COMMERCIAL BARRIERS AND INDUSTRY INCENTIVE PLANS}

\begin{abstract}
From the beginning of the 2008 financial crisis, trade barriers have been established around the globe as a means of defense industries and the economic health of their countries, fitting an emphasis on Brazil being one of the countries that practiced trade barriers in Latin America.In the same period Brazil incorporates the use of industrial policy explicitly called Productive Development Plan (PDP), succeeded by Major Brazil Plan (PBM), demonstrating openly protectionist view of the Brazilian state. Thus, the objective of this study is to investigate the level of protectionism in the Brazilian state and discuss to what extent it is guaranteed to strengthen the domestic industry in terms of competitiveness and innovation.
\end{abstract}

Key Words: Trade Barriers; Industrial Policy; Brazil.

\section{INTRODUÇÃOO}

A crise internacional promoveu uma espécie de volta ao passado em todo o mundo, os governos recorreram a instrumentos clássicos (barreiras alfandegárias e comerciais), além de profundos estímulos em sua economia na tentativa de diminuir o impacto da turbulência da crise financeira. Com o Brasil não foi diferente, cabe destacar que dos países da América Latina foi o segundo que mais aumentou suas barreiras alfandegárias e comerciais, segundo o OMC.

Destarte, além das medidas protecionistas, o Estado brasileiro parece querer se aproveitar do momento de crise para refazer um modelo de substituição de importações oriundo da década de 1930, mas com outra "roupagem", a de aceitar a livre competição do mercado e deixar as empresas brasileiras mais competitivas e internacionalizadas. 
Por isso, é com este objetivo que este artigo se propõe a investigar o nível das medidas protecionistas do Estado nacional no pós-crise de 2008, além dos planos de desenvolvimento produtivo que buscam a inovação e a diversificação da pauta de produtos de exportação no Brasil, principalmente os produtos com alto conteúdo tecnológico.

Dessa forma, este artigo está dividido em quatro seções incluindo esta introdução e as considerações finais (nomeada de "fortalecimento da indústria nacional ou novo modelo protecionista?"). Na segunda seção, discute se o nível de medidas protecionistas adotadas pela América Latina e no Brasil. Na terceira seção busca-se investigar os objetivos dos planos industriais no pós-crise e avaliar algumas medidas.

Na quarta e última seção é elaborada uma discussão sobre as duas seções anteriores e se realmente o incremento do protecionismo comercial utilizadas concomitantemente com as políticas de incentivo a modernização e a competitividade de indústria podem ou não serem utilizadas como uma forma de fortalecimento do setor industrial brasileiro.

\section{BARREIRAS COMERCIAIS}

Após seis anos de expansão do comércio mundial a uma taxa média de $16,3 \%$, as exportações levaram uma dura queda a partir da crise internacional. Em especial, as exportações Latino Americanas cresceram 16,8\%, de 2003 até 2008, mas diminuíram 22,5\%, já em 2009. As importações decresceram 24,7\%, depois de crescerem a uma taxa média anual de 17,4\%, durante os seis anos anteriores à crise (2003-2008) (ROZEMBERG e GAYÁ, 2010, p.2).

Existem muitos fatores que explicam essa queda acentuada a partir de 2009. Primeiro, a demanda mundial se contraiu $0,6 \%$, como resultado da recessão dos países desenvolvidos, gerando uma desaceleração das economias emergentes. Segundo, a queda nos preços dos commodities (-31\%) é um fator crucial para compreender a queda das exportações na América Latina, onde os produtos primários têm parcela significativa.

Dessa forma, o comércio mundial despencou devido a uma escassez de crédito (terceiro fator) e, em por último, houve um aumento moderado do protecionismo que contribuiu para a contração do comércio mundial (figura 1). 
Figura 1: Variação anual (em \%) das exportações e importações na América Latina em 2009

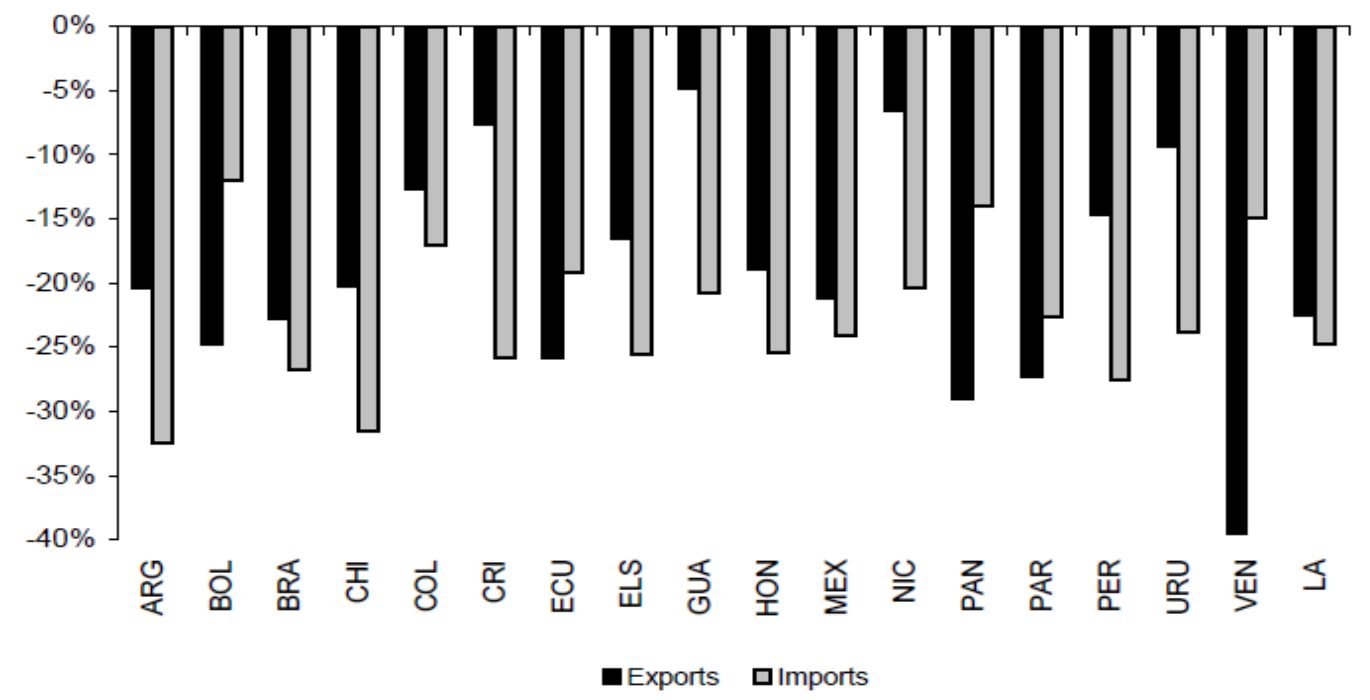

Fonte: Retirado de Rozemberg e Gayá (2010), dados do Global Trade Alert.

Nota: LA: Taxa média dos países selecionados.

Seguindo essa tendência, os países Latino Americanos foram forçados a se impor com barreiras comerciais como resposta para defenderem o comércio doméstico e a saúde de suas balança comerciais, cabendo destaque elevado para o Brasil, sendo o que criou em maior número medidas que prejudicam parceiros comerciais (figura 2).

Figura 2: Número de medidas que prejudicam parceiro específico

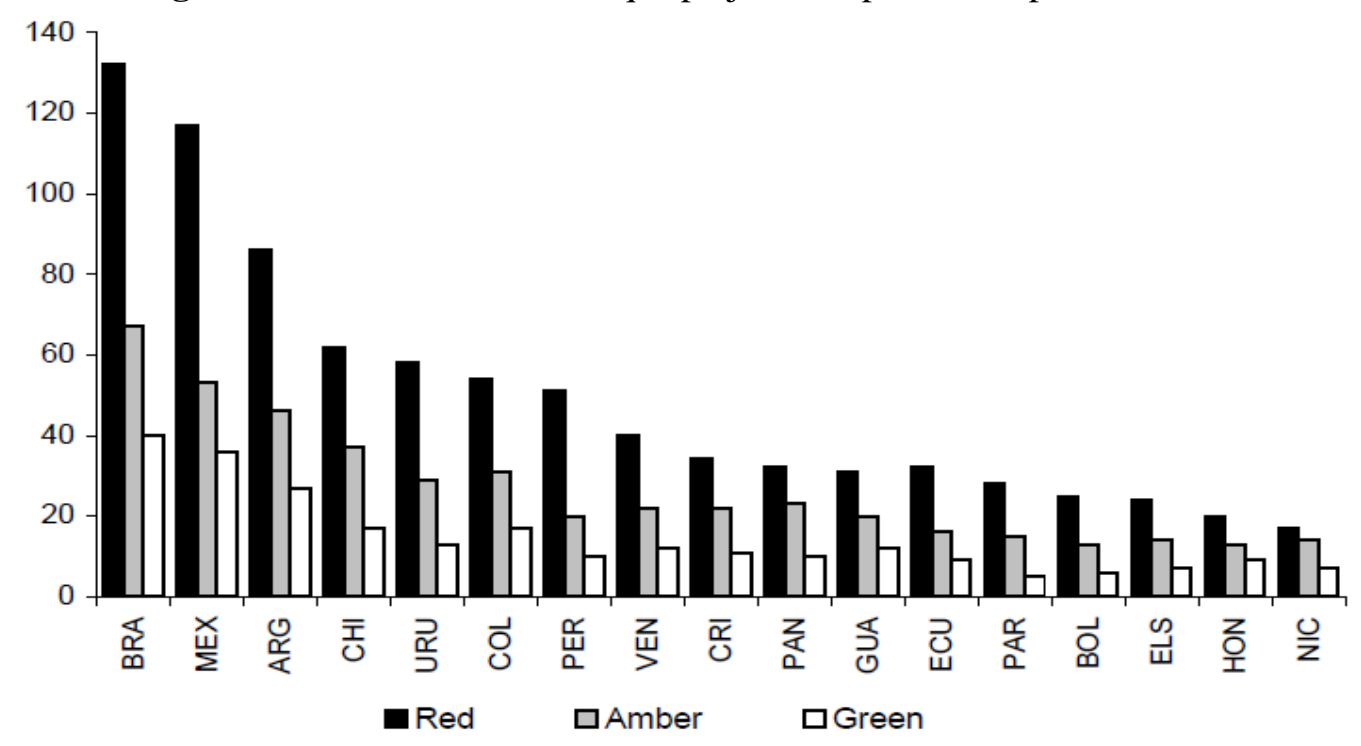

Fonte: Retirado de Rozemberg e Gayá, dados do Global Trade Alert ${ }^{1}$

Com relação a essas medidas que prejudicam a relação comercial, segundo legenda do Global Trade Alert (as medidas vermelhas e âmbar, que demonstram prejudicar as relações

\footnotetext{
${ }^{1}$ (i) verde, que envolvem a liberalização numa base não-discriminatória ou para aumentar a transparência, (ii) o âmbar, que pode envolver a discriminação contra interesses comerciais estrangeiros (incluindo as medidas já aplicadas e as medidas anunciadas ou em estudo que, se implementado, deve discriminar os interesses) e (iii) vermelha, que já estão em vigor e quase certamente irão discriminar interesses comerciais estrangeiros.
} 
comerciais) a Argentina é líder (na América Latina) com 69 restrições, seguido pelo Brasil e México (Figura 3). Mesmo assim, todos os países da América do Sul (mais o México e Costa Rica) são os mais afetados (por restrições que minam a saúde do comércio internacional) por restrições comerciais mais do que eles mesmos criam.

Figura 3: Número de medidas impostas para parceiros específicos

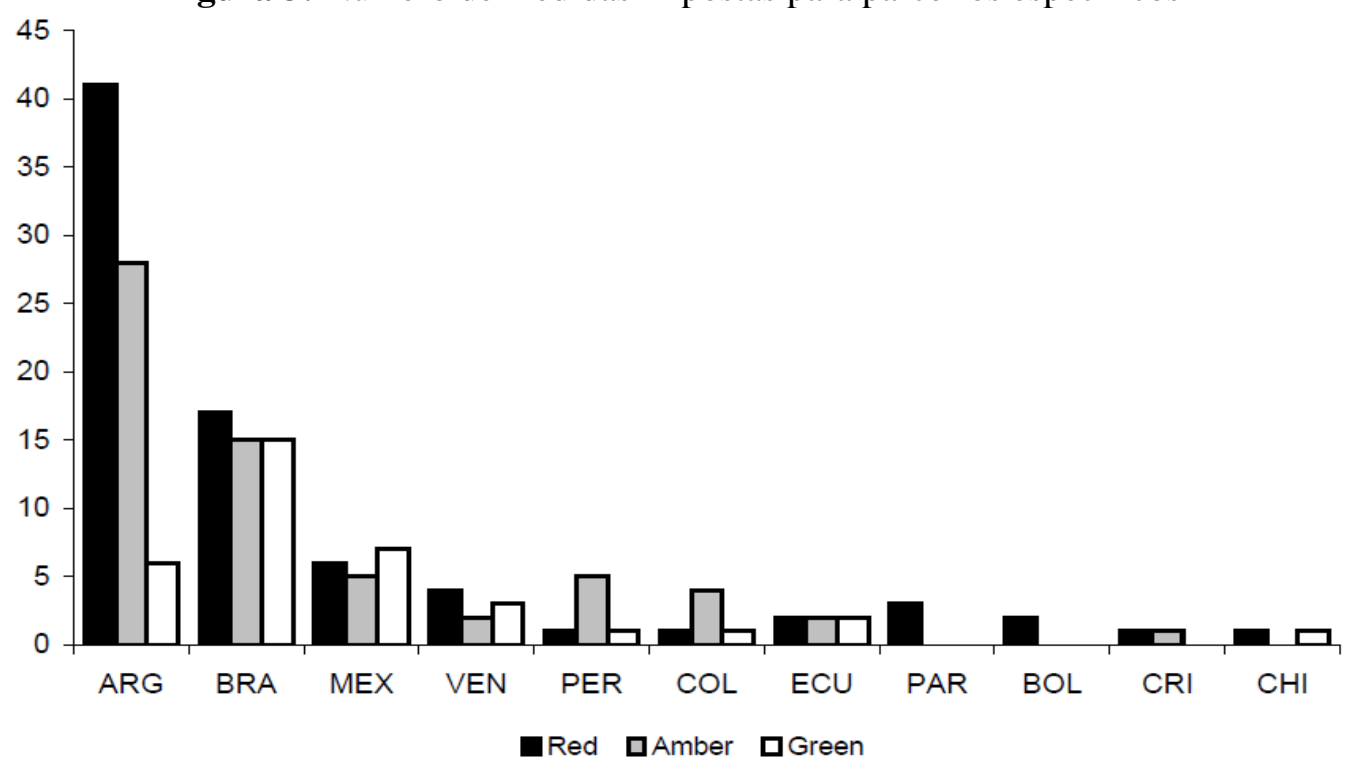

Fonte: Retirado de Rozemberg e Gayá, dados do Global Trade Alert.

No âmbito do Brasil, medidas protecionistas com relação a importação foram criadas logo após a crise financeira internacional, como a licença de importação automática para uma vasta gama de produtos, tendo início a partir de janeiro de 2009, dado a iminência de um possível déficit na balança comercial, depois de anos em superávit. Contudo, foi logo revogada após duras críticas da opinião pública e dos empresários que duvidaram dá agilidade do governo em conceder as licenças em tempo hábil (no máximo dez dias), conforme normas da Organização Mundial do Comércio (OMC).

Houve também um aumento nas tarifas de importação para minérios de ferro que antes possuíam taxa de zero por cento na lista de isenções da TEC (Tarifa Externa Comum) no âmbito do MERCOSUL e voltaram ao patamar original de $12 \%$ a 14\%. Tem sido frequente a alteração das tarifas de importação do governo, contudo, o governo continua diminuindo sua proteção para importações de bens de capital a fim de estimular investimentos.

De acordo com o LATN (2010), houve um aumento nas medidas de defesa comercial, as estatísticas demonstram que os casos ocorreram em maior incidência em 2008, antes da crise e, foi consequência das pressões decorrentes da valorização da moeda. Os processos antidumping iniciados pelo Estado brasileiro, tiveram reflexos positivos, ganhando na maioria dos casos iniciados (Figura 4), sendo a maioria dos casos contra a China. 
Figura 4: Processos iniciados Antidumping

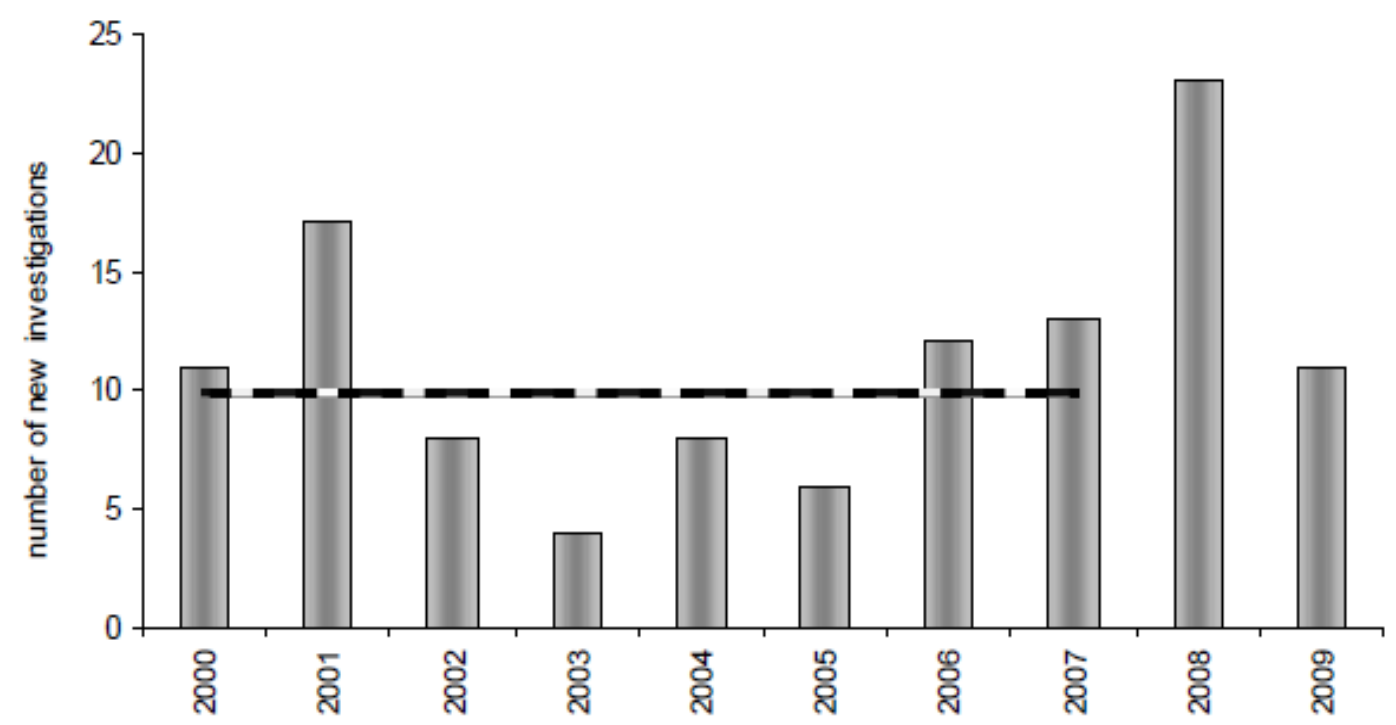

Fonte: Retirado de Latin American Trade Network, dados do Global Trade Alert.

\section{PLANOS INDUSTRIAIS}

A partir do início da década de 1980 assistiu-se a um processo de desuso de políticas de incentivo a indústria na América Latina, tanto por falta de recursos fiscais, encabeçada pelo endividamento dos Estados Nacionais, como por mudanças no campo da teoria econômica.

No Brasil, além do desuso de políticas específicas para estímulo da indústria já na década de 1980, iniciou-se um processo de privatização subsidiado pelo BNDES, para somente em 1999 voltar a utilizar os mecanismos que promovessem a indústria como ajuda de fundos setoriais criados no governo de Fernando Henrique Cardoso (ALMEIDA, 2009).

Após a crise financeira mundial, assiste-se no Brasil a um processo de elevações de barreiras comerciais e alfandegárias ao passo em que são criados projetos específicos sob a ideologia de fortalecimento da competitividade da indústria nacional, como veremos a seguir.

\section{PLANO DE DESENVOLVIMENTO PRODUTIVO}

Criada a partir de 12 de maio de 2008, a Política de Desenvolvimento Produtivo (PDP), em consonância com a Política Industrial, Tecnológica e de Comércio Exterior (PITCE), busca um aumento da competitividade sistêmica da indústria brasileira, sendo ela estruturada em três níveis. O primeiro busca estabelecer uma relação integrada entre a PDP e os demais programas de incentivo ao crescimento do governo, como o PAC, PAC-Saúde, PROMIMP, entre outros. Buscando reduzir custos e aumentar os recursos de investimento e inovação. 
O segundo nível se encontram setores que se beneficiam diretamente com o plano e fazem parte do que o governo chama de "setores estratégicos" para o desenvolvimento econômico do país, como: seis programas estratégicos (nanotecnologia; tecnologia da informação e comunicação; biotecnologia; energia nuclear; complexo industrial de defesa; e complexo industrial de saúde), sete programas com o objetivo de consolidar a liderança em setores em que já existe uma certa maturidade e uma colocação avançada em termos de produtividade mundial (petróleo; gás natural e petroquímica; mineração; siderurgia; celulose e papel; e carnes) e doze programas para incentivar a competitividade de setores consolidados na indústria nacional mas que não conseguem ser competitivos a nível global (indústria automobilística; indústria naval e cabotagem; couro; perfumaria, etc.).

Por último, o terceiro nível visa à expansão produtiva brasileira a nível regional e alguns projetos de integração com a África, visando novos mercados potenciais no longo prazo. Além da expansão das MPEs (setor que mais emprega no Brasil).

Um aspecto marcante da PDP é a ênfase em dar "sustentabilidade ao atual ciclo de crescimento", como o nível de crescimento econômico estava elevado até meados de 2008, esse era um dos principais objetivos da PDP, além do incentivo a inovação, também se necessitava de um estímulo ao aumento da capacidade produtiva, visando à eliminação dos gargalos de longo prazo (pressões inflacionárias e alteração da balança comercial).

Além disso, é notório as intenções do governo em expandir o nível de participação das micro e pequenas empresas (MPEs), criando crédito facilitado, objetivando a inovação e melhoria do campo da competitividade internacional, indicada pelo aumento da sua participação no peso das exportações.

O que mostra total interesse no esforço de diversificar a pauta de exportações em itens de conteúdo mais tecnológico, buscando assim, reverter o processo citado por Guerreiro (2012), de "especialização regressiva" no qual se buscou utilizar o até então bom momento da economia brasileira e a existência de um parque industrial já amadurecido, complexo e integrado para promover seu processo de agregação de valor nos produtos manufaturados.

Contudo, a PDP não propôs nenhum tipo de interferência na política macroeconômica, como a taxa de câmbio ou medidas comerciais de proteção frente a produtos manufaturados (não nos planos da PDP) importados. Utilizou-se apenas da pressão competitiva para impulsionar um estímulo de capacitações e produtividade dos produtores brasileiros, criando instrumentos que facilitassem e reduzissem o custo das atividades inovativas e do investimento produtivo.

Quanto ao quesito das metas a serem cumpridas, quatro foram às metas estipuladas como principal objetivo para o plano: 1. Elevar o nível de investimento (FBCF de 17,4\% em 
2007 para 21\% até 2010); 2. Elevar o nível de investimento em inovação (aumentar o P\&D de $0,57 \%$ em 2005 para 0,65\% em 2010); 3. Elevar a participação brasileira no comércio mundial (de 1,18\% em 2007 para 1,25\% em 2010); 4. Incentivar o aumento das exportações das MPEs (aumentar 10\% em relação à quantidade de MPEs de 2006).

No campo ex ante (as metas acima previstas) foram pré-determinadas contando com o mesmo desempenho econômico que o país vinha galgando até meados de 2008, cabendo uma ressalva de que o plano não tinha nenhum tipo de pretensão ambiciosa ou fora da realidade da economia brasileira. Por isso, após o prazo estipulado para chegar aos resultados esperados nas metas (ex post), dada o aprofundamento da crise econômica mundial, três delas não obtiveram êxito e uma obteve sucesso com ressalvas de alguns analistas.

No nível de instrumentos políticos para consecução dos objetivos da PDP, cabe destaque para a utilização de políticas de redução dos custos (tributários e de financiamentos) e da ampliação do nível de crédito e de subvenções para todos os setores citados acima, visando a manutenção do crescimento acelerado e da redução dos gargalos de longo prazo (citados anteriormente), na tentativa de reduzir o custo para a competitividade.

Além desses benefícios, outros instrumentos foram também utilizados, visando um estímulo produtivo, como o poder de compra governamental via empresas estatais e por meio da administração direta, como também instrumentos de regulação técnicas e de apoio técnico, visando facilitar e implementar a capacidade empresarial e de recursos humanos e da promoção comercial das empresas. Segundo Guerriero (2012, p. 8), "o apoio técnico, o poder de compra estatal e a regulação podem ser poderosos instrumentos de cobrança ou estímulos por obrigações e contrapartidas que poderiam ser implementadas para acelerar ou direcionar as decisões empresariais."

Quanto ao quesito da avaliação dos resultados das metas da PDP, cabe o ressalte que logo após o plano entrar em vigor (setembro de 2008), a falência do Lehman Brothers pouco tempo depois, marcou o início da crise econômica financeira e mundial e, consequentemente, a restrição do crédito e a alta volatilidade dos investidores restringiram os investimentos no Brasil e no resto do mundo, trazendo como consequência direta a não obtenção dos resultados esperados e um reposicionamento do governo quanto ao pensar em "crescimento continuado" para um pensar em "não entrar em recessão", como destaca IPEA (2009, p. 226) apud Guerriero (2012):

No último trimestre de 2008, o PIB caiu 3,6\% em relação ao terceiro trimestre e a taxa de investimento trimestral, que havia alcançado 20,4\% - quase a meta da PDP para 2010 - no terceiro trimestre, voltou aos $18,5 \%$ do início de 2008 . Tanto as exportações quanto as importações brasileiras, por sua vez, caíram aproximadamente $25 \%$ nos primeiros dois meses do ano em relação ao mesmo período do ano anterior. Além disso, uma das 
principais variáveis para manutenção dos investimentos na economia brasileira, o crédito, ficou mais caro e escasso, especialmente para empresas menores.

Dado a reviravolta da trajetória de crescimento continuado em que estava alicerçado o país, o governo lançou uma resposta rápida já no início de 2009, com os projetos Minha Casa, Minha Vida (concessão de crédito imobiliário facilitado para os setores de baixa renda) e o programa de sustentação do investimento (PSI), este último de maior interesse a política industrial (redução do custo de financiamento de bens de capital), ambos compatíveis inclusive com a proposta de redução do custo de financiamento nos moldes da PDP.

Muitas críticas foram feitas de inúmeros setores da indústria brasileira quanto às questões dos resultados que seriam objetivo da PDP, contudo, em tom uníssono, foi reconhecido a importante manifestação do governo em tornar explícito a retomada do processo de fortalecimento da indústria brasileira.

Cabe destaque a dinâmica da resposta do governo em acertadamente criar dois programas de incentivo ao consumo e à indústria, entrando em harmonia com os projetos já firmados, tais como o PAC e o PDP. Mostrando que, dada à conjuntura perversa observada, os objetivos não seriam mais de sustentar investimentos, mas sim de evitar o processo de recessão da economia brasileira.

Apesar de todos esses fatores e de um elogiado mecanismo de governança e de controle de medidas de política industrial, era de se esperar que ao mudar o foco (de manter um crescimento sustentado para o de evitar a recessão) e, dada as condições conjunturais da crise econômica, as metas não obtiveram êxito pleno².

Dado ao arrefecimento no comércio mundial, as perspectivas de investimentos se reduziram abruptamente e o nível de exportações teve apenas uma leve baixa, dado que a China manteve o nível de importações de commodities brasileiras (FIESP, 2011).

Como consequência, houve uma redução do lucro das empresas, que minou as metas de investimento e FBCF (são sensíveis à demanda futura esperada), de forma análoga, o aumento dos investimentos em P\&D, que tinha por meta um crescimento de $0,54 \%$ em relação ao PIB para $0,65 \%$ até 2010 também não foi alcançado.

Segundo as estimativas da FIESP (2011), houve uma contração no nível de investimento para 0,40\%; todavia, Guerriero (2012), argumenta que os dados subestimam a retomada do nível de crescimento econômico a partir de 2010, em que, na verdade, estimulou a demanda por recursos de crédito do BNDES e da FINEP para a atividade inovativa. Segundo dados oficiais (Brasil, vol.1: relatório de macrometas apud Guerriero, 2012 p.13) demonstram que houve crescimento em P\&D para um nível de $0,59 \%$ em relação ao PIB, contudo, ainda abaixo da meta esperada.

\footnotetext{
${ }^{2}$ Ver FIESP. A política de desenvolvimento produtivo após a crise (2009). 
A única e exclusiva meta cumprida da PDP foi a realização de expansão do nível de comércio internacional via exportações com certo nível de folga em relação à meta (1,35\% em participação no mercado mundial ante meta de 1,25\%), graças a manutenção das importações chinesas de produtos de commodities do mercado brasileiro. Porém, a submeta que tinha o objetivo de diversificar a pauta de exportação não foi cumprida, mostrando a dificuldade em expandir a competitividade da indústria brasileira.

Analistas da FIESP (2011) e IEDI $(2011)^{3}$ questionam o sucesso dessa meta pela total deficiência da PDP em conseguir promover um estímulo real para a diversificação da exportação em direção a produtos de maior valor agregado. Almeida (2009) cita que a grande concentração das operações de apoio financeiro e de financiamento do principal banco estatal ligado a projetos de incentivo a indústria (BNDES) foram destinados a setores e empresas que já mantinham níveis consideráveis de competitividade internacional, além de baixo valor agregado na transformação da manufatura (petróleo, mineração, etc.) quando deveria buscar estimular setores em que estão numa fronteira tecnológica mais avançada.

Como condição para esse processo de expansão da diversificação da pauta para produtos de alto valor agregado um dos grandes objetivos era a de expandir a participação das MPEs na pauta de exportação, porém além de não lograr em sucesso houve uma redução do número de MPEs que participavam da pauta de exportações nacional. Devido também, a inúmeros fatores que reduzem a competitividade das empresas brasileiras (taxa de câmbio, impostos elevados, alta carga trabalhista, etc.) e a crise internacional.

Existem certas divergências quanto à avaliação do balanço de resultados da PDP, sendo a FIESP (2011) a mais crítica, pois, considera que além de não alcançar seus objetivos não conseguiu deter o processo de desindustrialização, mostrando falta de ousadia dos instrumentos da PDP em apenas utilizar instrumentos de desonerações pontuais e ao estímulo de linhas de crédito pouco satisfatórios. Quanto ao IEDI (2011), cabe destaque para um aspecto positivo da PDP que é a de retornar de forma explícita os objetivos do fortalecimento da indústria brasileira, harmonizando as medidas ao cenário mundial de política industrial (sem minar a concorrência internacional).

Concomitantemente, IEDI (2011) e FIESP (2011), concordam que deveria haver mais ousadia no uso dos instrumentos de "compras governamentais", buscando alavancar o desenvolvimento industrial, sem restringir os princípios de concorrência.

Dessa forma, podemos perceber que dado o curto espaço de tempo das ações do Plano de Desenvolvimento Produtivo, ela foi positiva, no geral, por seu esforço em

\footnotetext{
${ }^{3}$ VerIEDI. Indústria e política no Brasil e em outros países. 2011
} 
sinalizar uma nova política de incentivo a competitividade da indústria nacional deixado para trás a partir do início dos anos 1980.

Seguindo a mesma linha de raciocínio da busca da competitividade da indústria nacional, é implementado em agosto de 2011 o Plano Brasil Maior que elenca metas parecidas e aproveita o know-how da PITCE e da PDP, que será discutido na próxima seção.

\section{PLANO BRASIL MAIOR}

À época do lançamento do PDP o cenário global era outro até então e, por isso, os objetivos se concentravam em apenas dar continuidade às metas de crescimento econômico vivenciado desde o boom das commodities brasileiras a partir de 2002, graças a sua parceira comercial China.

Em um cenário totalmente adverso é lançado o Plano Brasil Maior em 2 de agosto de 2011, visto como um programa oportuno dentro de um setor industrial que agonizava e se preocupava com um processo de desindustrialização alarmante devido à alta competitividade da manufatura internacional, aliado a valorização de nossa moeda que mina a nossa dinâmica competitiva, dentro de um comércio internacional dominado por manufatura barata.

Além da necessidade do governo em manter os níveis de crescimento ainda tem o desafio de tornar a indústria brasileira competitiva e altamente tecnológica e, dentro de um mercado ainda aquecido, tem que estimular o investimento em ampliação da capacidade da oferta industrial se não quiser enfrentar períodos de pressões inflacionárias e desestabilizar a balança comercial.

Por isso, dado o aprendizado de políticas de desenvolvimento industrial, iniciado pela PITCE (antes da crise, no governo Lula) e logo depois pela Política de Desenvolvimento Produtivo (PDP), o Plano Brasil Maior possui uma maior abrangência de instrumentos e tende a ser mais ambiciosa do que os modelos anteriores. Levando em consideração que o governo crê que ainda há um alto nível de consumo potencial e de investimento a nível nacional como cita (SARTI e HIRATUKA, 2011 apud GUERRIERO, 2012, p.18) e, por isso o mercado doméstico será o principal agente de sustentação do crescimento das empresas.

O aumento desproporcional das importações e a perda de competitividade das exportações de manufaturados constituem-se nos maiores obstáculos ao investimento industrial e à geração de empregos e renda e, portanto, à constituição do ciclo virtuoso de crescimento liderado pelo investimento e pela indústria. Isto porque se, por um lado, as perspectivas de expansão da demanda (consumo e investimento) são bastante positivas, por outro, há um risco não desprezível com relação à capacidade de oferta competitiva da indústria brasileira, permitindo que uma parcela considerável da expansão da demanda seja desviada para o exterior via aumento do coeficiente e conteúdo importados. A expansão exponencial das importações deve ser objeto de preocupação e não se trata de defender uma política inadequada e ineficiente de substituição de importações e sim da lógica de montagem de um ciclo virtuoso de crescimento liderado pelo investimento e pela indústria e da estratégia de utilizar o mercado doméstico como espaço privilegiado de acumulação e centralização de capital. 
Como a o Plano Brasil Maior (PBM) ainda está em vigor (2011 - 2014), cabe fazer algumas considerações quanto as suas metas e objetivos, não cabendo aqui uma análise de avaliação de resultados, observando que a PBM admite adaptação e correção nos rumos desejados ao longo do processo (demonstrando ser mais dinâmica do que nos planos anteriores).

Quanto as suas metas até 2014, vale destacar os 10 principais objetivos: 1. Elevação da FBCF de 18,5\% do PIB em 2010 para 22,4\%; 2. Aumentar o nível de P\&D de 0,59\% até 0,9\%; 3. Aumentar a qualificação de funcionários com grau de nível médio na indústria de 53,7\% para 63\%; 4. Aumentar a razão do Valor de transformação industrial/ Valor Bruto da produção (VTI/VBP), de 44,3\% para 45,3\%; 5. Aumentar a fatia de participação da indústria intensiva em conhecimento, de 30,1\% para 31,5\%; 6. Fortalecer as MPEs inovadoras; 7. Diminuir o consumo industrial de energia; 8. Diversificar as exportações brasileiras e ampliar a participação no comércio internacional de 1,36\% para 1,6\%; 9. Aumentar a participação nacional nos mercados de tecnologia, bens e serviços para energia, de $64 \%$ para $66 \%$; 10. Ampliar o número de domicílios urbanos com acesso à banda larga. ${ }^{4}$

Para o cumprimento dessas metas serão utilizados instrumentos já antes utilizados pela PDP, como a desoneração do investimento, exportações e gasto em atividades de inovação, além de uma inovadora lei de compras governamentais que autoriza a compra de produtos produzidos segundo as normas técnicas do Brasil, por preços $25 \%$ superiores, além da desoneração dos salários.

Outro ponto inovador da PBM é a criação da Empresa brasileira de Pesquisa e Inovação Industrial (Embrapii) nos moldes do já bem conhecido Embrapa, no qual, se destina a promover a inovação em projetos em fase pré-competitiva, junto com o setor privado.

Do campo da análise sobre as metas estabelecidas do Plano Brasil Maior vemos pouca ousadia com o plano anterior, pois, ainda falha em desenvolver um projeto em um espaço de tempo muito curto para guiar em direção ao desenvolvimento à indústria brasileira.

Pode-se destacar que os dois primeiros objetivos da PBM (elencadas anteriormente) seguem a mesma linha lógica da PDP em buscar aumentar os investimentos e gastos em P\&D no Brasil, por serem considerados os motores para o crescimento e desenvolvimento do mesmo. Guerriero (2012) cita a falta de ousadia da terceira meta que tem por objetivo aumentar a qualificação dos trabalhadores da indústria apenas para o nível médio o que limita as intenções do próprio governo em alavancar a indústria de conteúdo altamente tecnológico.

A quarta e quinta meta é interessante, pois buscam ampliar a fatia de conteúdo de valor tecnológico na indústria, sendo que a 4 e 9 juntas se assemelham ao antigo modelo de substituição de importações.

\footnotetext{
${ }^{4}$ Ver IEDI.Uma Análise de Plano Brasil Maior. (2011)
} 
A sexta mantém o compromisso quanto ao quesito das Micro e Pequenas Empresas (MPEs) exportadoras, porém, deixando de lado a sua mensuração via nível de inserção no comércio internacional e buscando identificar aquelas que possuem maior habilidade inovadora.

A meta sete supriu uma lacuna questionada no PDP que é a busca ao incentivo do desenvolvimento de uma política industrial sustentável que busca poupar recursos naturais escassos. A oitava meta segue a mesma linha do plano anterior, mas com uma entonação mais explicita quanto à necessidade de diversificar a pauta dos produtos para exportação.

Enquanto que a décima entra em consonância com o Programa Nacional de Banda Larga (PNBL), já que para o governo a expansão da banda larga é estratégica para disseminação de conteúdo educacional e do acesso a serviços no mundo atual. Sendo-a usada para incluir metas de desenvolvimento tecnológico ou até mesmo para aquisição de equipamentos produzidos no Brasil (o que incentiva a indústria nacional).

\section{FORTALECIMENTO DA INDÚSTRIA NACIONAL OU NOVO MODELO PROTECIONISTA?}

No âmbito de se discutir o que foi investigado nas duas seções anteriores em que se constata um novo desafio para a economia brasileira, formado dentro de um cenário mais protecionista, o Estado brasileiro tem por objetivo o desafio de incentivar, por meio do mercado doméstico, a manutenção das taxas de crescimento econômico, criando planos de incentivo a indústria nacional, além de estimular investimentos e a criar a cultura de processos inovativos dentro de setores já bem formados e de novos setores que possuem alto conteúdo tecnológico, tornando os setores da indústria brasileira mais competitiva em nível internacional, algo visto apenas no modelo de substituição de importações entre 1930 e 1980 do século XX.

Embora, o processo de estímulo à época visava o fechamento da economia brasileira para o comércio internacional, diferentemente das novas metas do governo que busca a internacionalização das empresas brasileiras por meio da competitividade, segundo cita (GUERRIERO, 2012, p. 16).

\footnotetext{
Em primeiro lugar, a política industrial, enquanto política de promoção da competitividade deve serindissociável da concorrência, da atualização tecnológica e do aumento da produtividade, não sendoseus objetivos criar e disseminar setores e empresas privilegiadas, ineficientes e que sobrevivam àsombra da proteção e do subsídio.
}

Diante disto Peres (2006) apud Almeida (2009, p.15), o ressurgimento da política industrial na América Latina, pode ser dividido em quatro grandes grupos de políticas de promoção a competitividade. 
O primeiro grupo é formado por políticas de fomento setorial que, na maioria dos casos, representam a continuação das políticas adotadas no período de substituição de importações com o objetivo de aumentar a competitividade de setores que já existem, visando novos elos na cadeia produtiva.

O segundo grupo representa o conjunto de políticas setoriais de cunho neoschumpeteriano, onde destaca o papel estratégico da inovação no desenvolvimento da economia, enfatizando o conhecimento tácito e da criação de um aparato institucional que favoreça a inovação. Assim, destaca-se a criação de setores mais intensivos em tecnologia, como as tecnologias de inovação e comunicação (TICs), a nanotecnologia, a biotecnologia, etc., como se têm visto na PDP e na PBM.

Já o terceiro grupo de políticas de promoção à competitividade, adotadas pelos países da América Latina, assistisse a busca pela promoção de setores que foram privatizados nos anos 1990, no qual o Estado passou a ser regulador. Esses setores são geralmente intensivos em capital e estão sujeitos a rendimentos crescentes de escala (setor elétrico, telecomunicação, gás natural e petróleo). A política para esse setor está ligada ao desenvolvimento de um ambiente regulatório adequado, que facilite o aumento do investimento público e privado.

O último grupo de políticas de promoção à indústria na América Latina está intimamente ligado aos modelos de política de desenvolvimento regional do Brasil. Identificado como políticas de incentivo a pequenas e médias empresas em clusters ou em Arranjos Produtivos Locais (APLs), como forma de estimular o desenvolvimento local. Esse tipo de política é feita com o intuito de incentivar as externalidades positivas, decorrentes da aglomeração espacial, que favorece a atração de fornecedores, estímulo de mão de obra qualificada, etc.

Para Furtado (2004) apud Almeida (2009, p. 18), a diversificação produtiva da indústria nacional se caracteriza como uma vantagem competitiva para o Brasil, dessa forma, a política industrial deve focar no desenvolvimento de capacidades comerciais, financeiras e inovativas, se deseja promover o crescimento das exportações da indústria brasileira. Buscando o incentivo à internacionalização das empresas brasileiras e a formação de empresas líderes.

Observa-se que diante dos quatro grupos de incentivo a indústria, o Brasil tem criado um modelo híbrido, juntando os quatros grupos para desenvolvimento da indústria nos níveis, internacionais, nacional e regional. Contudo, embora a sinalização do governo em tornar explícito o desejo de estimular o setor industrial para um caminho de expansão tecnológico e de modernidade, os programas ainda carecem de instrumentos que permitam mais ousadia e que cobrem metas das empresas para quecontinuem se beneficiando com os inúmeros subsídios criados com o objetivo de reduzir o custo de produção das empresas. 
Assim, percebe-se que a defesa da concorrência, implementada logo no pós-crise, por meio de processos antidumping e o estímulo ao investimento e aos gastos em P\&D é o primeiro passo para uma transformação estrutural da economia brasileira.

\section{REFERÊNCIAS BIBLIOGRÁFICAS}

ALMEIDA, M. Desafios da Real Política Industrial Brasileira do século XXI. Texto para discussão n.1458. IPEA. 2009.

BRASIL. Plano Brasil Maior - Inovarpara competir. Competir para crescer. Plano 2011/2014. Texto de Referência. http://www.brasilmaior.mdic.gov.br/wpcontent/uploads/2011/11/plano_brasil_maior_texto_de_referencia_rev_out11.pdf.

CANO, W. e SILVA, A. L. G. A política industrial no governo Lula.Texto para discussão IE/UNICAMP no. 181. Mimeo. 2010.

CNI. Avaliação da política de desenvolvimento produtivo. Brasília, Maio de 2008.

EUZÉBIO, G. L. Protecionismo - o jogo perigoso do xadrez mundial. Desafios do desenvolvimento, IPEA. Disponível em:http://www.ipea.gov.br/desafios/index.php?option=com content\&view=article\&id=1227:reportagensmaterias\&Itemid=39.

FIESP. A política de desenvolvimento produtivo - a PDP após a crise. Decomtec - cadernos de política industrial, $\mathrm{n}^{\circ} 3$, Novembro de 2009.

FIESP. Plano Brasil Maior 2011-2014: análise dos instrumentos. Decomtec - Agosto de 2011.

GUERRIERO, Ian Ramalho. A recente política industrial brasileira: Política de Desenvolvimento Produtivo e Plano Brasil Maior. SEP, 2012.

IEDI. Uma análise do Plano Brasil Maior. Carta n 486, 23 de Setembro de 2011.

IEDI. Indústria e Política Industrial: no Brasil e em outros países. Maio de 2011.

LATN. Brazilian Trade Policy: New Motivations and Trends. CINDE, Setembro de 2010.

ROZEMBERG, R. e Gayá, R. Global crisis and trade barriers in Latin America.The $7^{\text {th }}$ Global Trade AlertReport, 2010.

WTO.Report to the Trade Policy Review Body from the director-general on trade-related developments.28 de junho de 2012 . 